\title{
Investigation of the effect of watercress via nuclear factor- E2-related factor-2 pathway on 7,12-dimethylbenz[a] anthracene-induced oxidative damage in rat liver
}

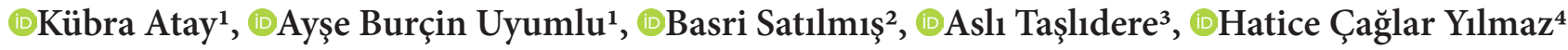 \\ ${ }^{1}$ İnönü University, Faculty of Pharmacy, Department of Biochemistry, Malatya, Turkey \\ ${ }^{2}$ İnönü University, Hepatology Research Laboratory, Institute of Liver Transplantation, Malatya, Turkey \\ 3̇nönü University, Faculty of Medicine, Department of Histology and Embryology, Malatya, Turkey \\ ${ }^{4}$ İnönü University, Faculty of Arts and Science, Department of Chemistry, Malatya, Turkey
}

Cite this article as: Atay K, Uyumlu AB, Satılmış B, Taşlıdere A, Çağlar Yılmaz H. Investigation of the effect of watercress via nuclear factor-E2related factor-2 pathway on 7,12-dimethylbenz[a] anthracene-induced oxidative damage in rat liver. J Health Sci Med 2021; 4(6): 936-942.

\begin{abstract}
Aim: Nuclear factor E2-related factor-2 (Nrf2) regulates many cytoprotective antioxidants, and detoxifying enzymes, has been a hopeful approach for chemoprevention of cancer. We researched the chemopreventive impact of watercress on the DMBAinduced oxidative damage in the rat liver via the Nrf2/ARE signalling pathway in the present study.

Material and Method: Female Wistar albino rats have categorized into three groups. The control was the first group, rats in the second and third groups were administered 7,12-dimethylbenz[a] anthracene (DMBA) $(20 \mathrm{mg} / \mathrm{kg}$ b.w., i.p.) and rats in the third group were given daily doses of watercress $(250 \mathrm{mg} / \mathrm{kg}$ b.w. Nasturtium officinale R.Br. for 4 weeks by oral gavage). Antioxidant and phase II detoxification enzyme activities, Nrf2 transcription factor level in liver, and serum ALT were determined. Also, histopathological analysis of the liver was performed.

Results: We observed that watercress induces DNA-binding of Nrf2. It was related to increased enzyme activities of phase II detoxifying and the antioxidant. Our results also demonstrated that watercress ameliorated liver injury.

Conclusion: Our data ensured considerable evidence that the dietary watercress ameliorates DMBA induced liver toxicity via regulating the activation of the Nrf2/ARE pathway which increases the expression of cytoprotective enzymes.

Keywords: Watercress, Nrf2, DMBA, xenobiotic enzymes, hepatoprotective effect
\end{abstract}

\section{INTRODUCTION}

Cancerincidence of theworld and its mortalityisassociated with lifestyle and environmental agents like food and chemicals. Sustained exposure to chemicals directly or indirectly leads to increase cancer risk by participating in all aspects of carcinogenesis (1). Polycyclic aromatic hydrocarbons (PAHs) are xenobiotic compounds that are environmental contaminants. PAHs are lipophilic and metabolized by xenobiotic-metabolizing enzymes (XMEs) (2). Firstly, enzymes of cytochrome P 450 family 1 that includes CYP1A1, CYP1A2, and CYP1B1 oxidize lipophilic compounds and generates reactive metabolites that interact with protein and DNA. Secondly, highly reactive compounds are converted to more hydrophilic species and/or inactivated by enzymes of phase II detoxification such as glutathione-S-transferase (GST), UDP -glucuronosyltransferases, heme oxygenases-1
(HO-1), $\mathrm{NAD}(\mathrm{P}) \mathrm{H}$ : quinine oxidoreductase 1 (NQO1), and sulfotransferases (3).

DMBA is one of the PAHs that is mainly found in automobile exhaust, cigarette smoke, grilled foods (4) which leads to the generation of reactive oxygen species (ROS), causing oxidative damage and decreased antioxidant defense enzymes, and increases carcinogenicity and toxicity (5). DMBA causes liver toxicity through the released carcinogenic metabolites as a result of xenobiotic metabolism (6). Normally Nrf2, is sensitive to redox changes, exists in an inactive form with a cytosolic inhibitor called Kelch-like epichlorohydrinassociated protein 1 (Keap1). Oxidative stress generating factors including electrophiles, xenobiotics, heavy metals, UV radiation, and physiological stress lead to cleavage of Nrf2 from the Nrf2-Keap1 complex. Nrf2 translocates to 
the nucleus and binds to the antioxidant response element (ARE). This causes the transcription of genes of phase II enzymes including NQO1 and GST (7). Excessive ROS generation due to the xenobiotic metabolism of DMBA causes oxidative stress, liver damage, and carcinogenesis. The Nrf2/ARE binding results in the induction of detoxification enzymes, antioxidative stress proteins, and other defense mechanisms (8).

Watercress belongs to the Cruciferae, also called Brassicaceae, family and is one of the perennial freshwater macrohydrophytes that has ecological and economic importance. It has been used by humans for many years both for food and medical purposes (9). This plant has some medicinal properties such as a diuretic (10), antihypertensive (11), antidiabetic (12), antihyperlipidemic (13), antiasthmatic, antituberculosis (14), and anticarcinogenic (15). Furthermore, it contains vitamins (Vitamin A and C), phenolic compounds, minerals, and glucosinolates (16). Glucosinolates are converted to isothiocyanates (ITC) non-enzymatically by physical factors or enzymatically by myrosinase during food preparation, cooking, and chewing (17). Phenethylisothiocyanate (PEITC) in watercress, is an ITC, has been extensively investigated as the most promising chemopreventive compound (18).

In this study, we hypothesized that watercress-mediated Nrf2 activation is a novel hepatoprotective pathway. The goal of this study was to evaluate the chemopreventive effect of watercress grown in the Malatya region of Turkey on oxidative liver injury induced by DMBA via the Nrf2/ARE pathway.

\section{MATERIAL AND METHOD}

\section{Animals and Experimental Design}

All experimental procedures of animals were approved by the Local Ethics Committee of the Animal Experiments of İnönü University (Date: 20/02/2015, Decision No: 2015/A-25). Twenty-seven female Wistar albino rats (weighing 150-250 g) accommodated in a room kept at $22^{\circ} \mathrm{C}$ with a 12-hr light/dark cycle and had free access to food. Rats were separated randomly into three groups ( 9 rats per group): Rats in group I served as control and were injected intraperitoneally with corn oil. Rats in group II (DMBA) and group III (DMBA+watercress) were injected intraperitoneally with DMBA $(20 \mathrm{mg} / \mathrm{kg}$ body-weight in corn oil) (Sigma-Aldrich, USA) (19). Rats in group III were given daily doses of watercress (Nasturtium officinale R.Br) (250 mg/kg b.w) for 4 weeks by oral gavage before intraperitoneal injection of DMBA $(20 \mathrm{mg} / \mathrm{kg}$ bodyweight in corn oil). After 30 days, under xylazine/ketamine anesthesia blood of rats in all groups was collected and then liver tissues of the rats were resected, washed in phosphate buffer, and rapidly frozen at $-80^{\circ} \mathrm{C}$.

\section{Plant Material and Extraction}

Nasturtium officinale R.Br were obtained from the pond in Arguvan country, city of Malatya, Turkey. A voucher specimen (No: 1001) was deposited into a herbarium at the Faculty of Pharmacy of İnönü University in Malatya, Turkey (Figure 1). Samples were freeze-dried and were powdered. The powdered sample was extracted with $70 \%$ methanol by heating at $70^{\circ} \mathrm{C}$ for 30 minutes and filtered. This procedure was carried out two more times and then centrifuged at $4000 \mathrm{rpm}$ for $10 \mathrm{~min}$. The solvent was removed with a rotary evaporator (Heidolph Laborota 4011-digital) at $90 \mathrm{rpm}$, and $45^{\circ} \mathrm{C}$ for $2 \mathrm{~h}$ and dried.
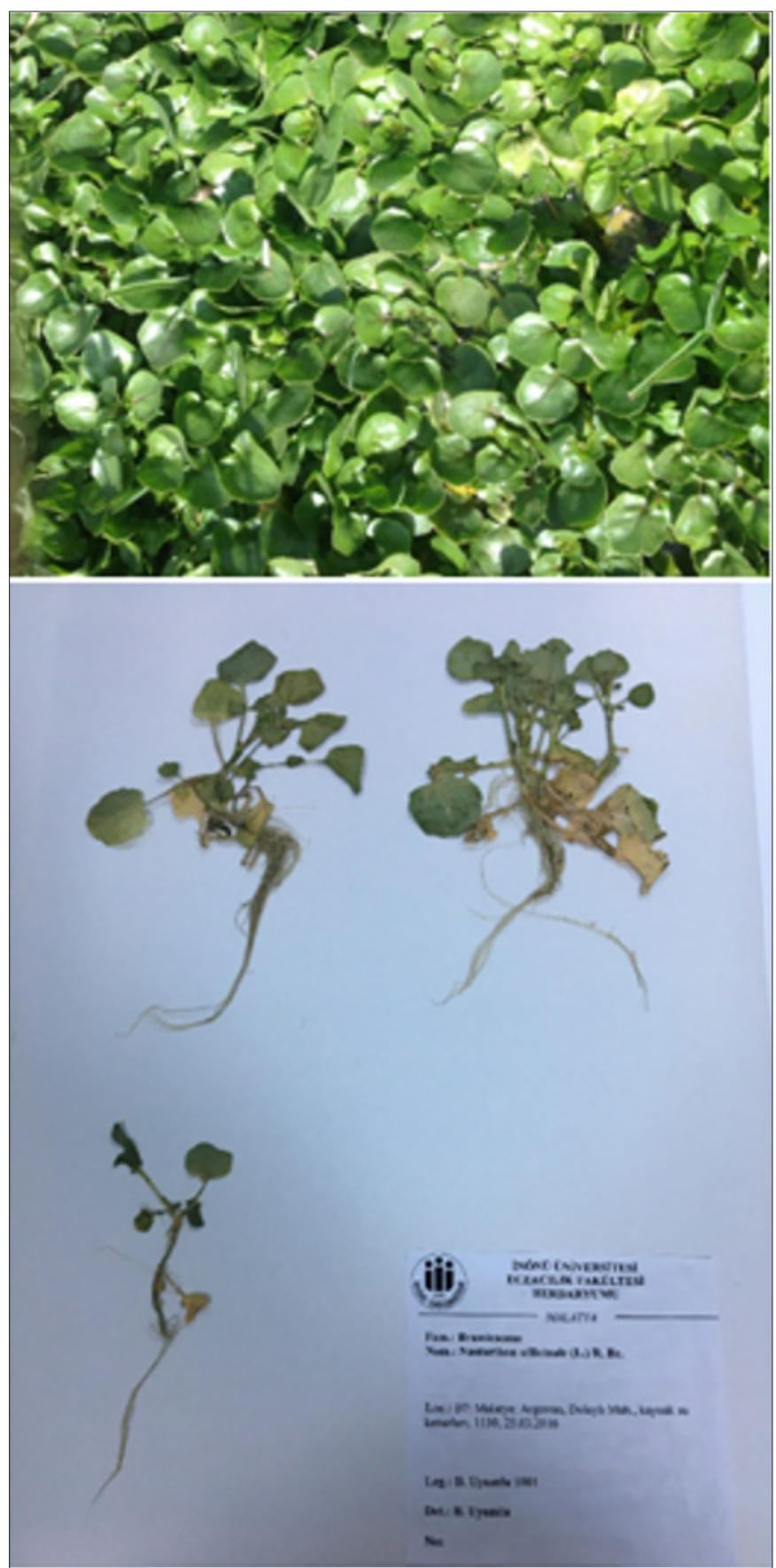

Figure 1. The aerial parts of Nasturtium officinale R.Br. were collected from the pond in Arguvan country, city of Malatya, Turkey (Fresh plant and a voucher specimen (No: 1001)) 


\section{Determination of PEITC Content of the Watercress}

The PEITC content of the watercress was determined by HPLC. PEITC standards were prepared with acetonitrile at concentrations of $0.312,0.625,1.25,2.5,5$, and $10 \mathrm{ppm}$. $100 \mu \mathrm{L}$ of the cyclocondensation working reagent $(10 \mathrm{mM}$ 1,2 benzene dithiol isopropanol and $\mathrm{pH} 8.5$ phosphate buffer) was mixed and incubated at $65^{\circ} \mathrm{C}$ for $2 \mathrm{~h}$. For the determination of PEITC amount is needed the conversion of glucosinolates to isothiocyanates and derivatization of the isothiocyanates by a cyclocondensation reaction. $2 \mathrm{mg}$ of dry watercress powder was solved in $2 \mathrm{~mL}$ deionized water and added $1 \mathrm{~mL}$ myrosinase. It was incubated at $37^{\circ} \mathrm{C}$ for $2 \mathrm{~h}$, and centrifugated at $875 \mathrm{~g}$ for $15 \mathrm{~min}$. It was derivatized by cyclocondensation reaction before HPLC analysis (20). For the chromatographic separation method in HPLC (Agilent 1100, Germany), a C18 column $(150 \times 4.6 \mathrm{~mm}$ i.d., $5 \mu \mathrm{m}$-ACE columns) and a mobile phase (Methanol-water $(90: 10, \mathrm{v} / \mathrm{v})$ were used. It flowed at $1.1 \mathrm{~mL} /$ min and was measured at $365 \mathrm{~nm}$. The amount of PEITC was calculated according to the calibration curve of PEITC standards. The correlation coefficient was found to be 0,999 for PEITC (Figure 2). The amount of PEITC in watercress was expressed as $\mu \mathrm{g}$ PEITC per mg of watercress.

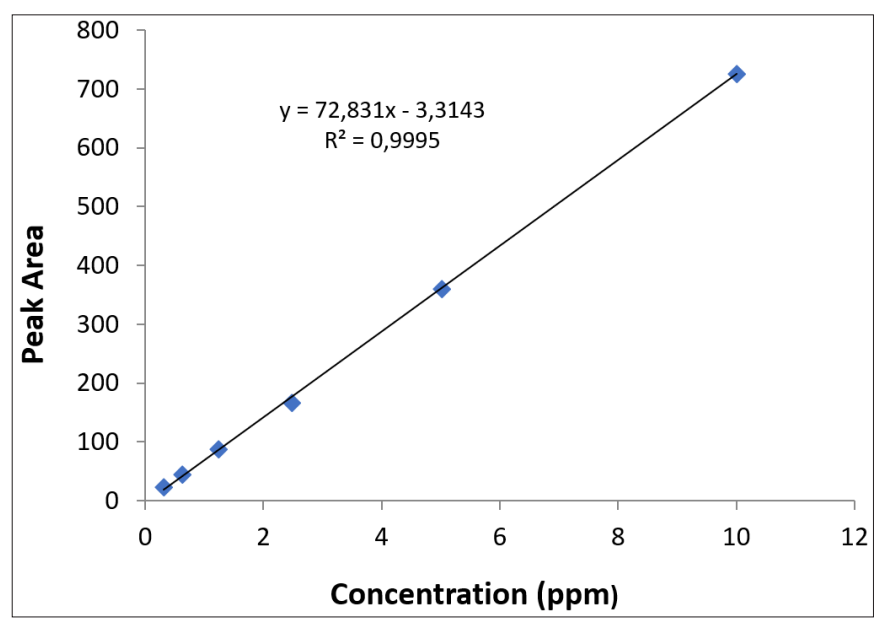

Figure 2. Calibration curve of standard solutions of PEITC.

\section{Biochemical Analysis}

Determination of protein content of liver tissues: The protein levels in the liver tissues were measured by the method of Bradford using BSA as the standard (21). Protein levels were expressed as milligram protein.

Determination of alanine aminotransferase (ALT): Rat ALT ELISA kit (Elabscience) was used to measure ALT level in the rat serum, according to the manufacturers' instructions. ALT level was expressed as $\mathrm{ng} / \mathrm{mL}$.

Determination of superoxide dismutase (SOD) activity: The SOD activity was measured using the Nitroblue tetrazolium (NBT) assay as described by Beauchamp and Fridovich (22). NBT-formazan was spectrophotometrically determined at $560 \mathrm{~nm}$. SOD activity was expressed as $\mathrm{U} / \mathrm{mg}$ protein.
Determination of glutathione peroxidase (GPx) activity: GPx activity was determined by the method of Lawrence and Burk (23). The absorbance at $340 \mathrm{~nm}$ was recorded for $1 \mathrm{~min}$. GPx activity was expressed as U/mg protein.

Determination of catalase (CAT) activity: CAT activity was determined by the method of Luck (24). The absorption was detected spectrophotometrically at $240 \mathrm{~nm}$ for $1 \mathrm{~min}$. CAT activity was expressed as $\mathrm{U} / \mathrm{mg}$ protein.

Determination of malondialdehyde (MDA): Amount of MDA was measured using the method of Mihara and Uchiyama (25). The absorption at $532 \mathrm{~nm}$ was recorded using 1,1,3,3-tetramethoxypropane as the standard. MDA content was expressed as nanomoles per milligram protein.

Determination of GST activity: GST activity assay kit (Cayman) was used to determine the activity of GST in the rat liver, according to the manufacturers' instructions. The absorption was monitored at $340 \mathrm{~nm}$. GST activity was expressed as $\mathrm{nmol} / \mathrm{min} / \mathrm{mg}$ protein.

Determination of NQO1 activity: NQO1 activity assay kit (Abcam) was used to determine the activity of NQO1 in rat liver, according to the manufacturers' instructions. The absorbance was detected at $440 \mathrm{~nm}$. NQO1 activity was expressed as $\mathrm{U} / \mathrm{mg}$ protein.

Determination of Nrf2-DNA binding activity: To measure the DNA binding activity of Nrf2 in liver nuclear extracts Nrf2 Transcription Factor Assay Kit (Cayman) was used.

\section{Histological Analysis}

The liver tissues were fixed in $10 \%$ formalin solution for $24 \mathrm{~h}$. Following embedded in paraffin, sections of the liver tissue were cut at $5 \mu \mathrm{m}$ and stained with hematoxylin-eosin (H-E) and Masson's trichrome methods. These samples were examined under light microscopy (Leica Micros Imaging Solutions Ltd., Cambridge, UK). The microscopic score of each tissue was calculated as the sum of the scores given to each criterion. Scores were given as absent (0), slight (1), moderate (2), and severe (3) for each criterion. The maximum score was 9 .

\section{Statistical Analysis}

The IBM SPSS software version 22 was used for data analysis. Whether the data showed normal distribution was analyzed according to the Kolmogorov-Smirnov Test. For the data that had normal distribution, the One-Way ANOVA test was used for statistical analyses. The Posthoc LSD Test was used for the comparisons among the groups. For the data that didn't have a normal distribution, the Kruskal-Wallis test and the Post-hoc Mann-Whitney $\mathrm{U}$ test were used. Arithmetic mean \pm Standard Deviation (SD) was used for the biochemical data. Differences were considered significant when $\mathrm{p}$ values were less than 0.05 and 0,0001 for the biochemical and histological data, respectively. 


\section{RESULTS}

\section{Histological Findings}

Histopathological analysis results were given in Table $\mathbf{1}$. The liver tissues of the control group did not present any histopathological alterations and significant damage was shown in the liver tissue of the DMBA-treated group ( $\mathrm{p}$ $<0.0001$ ). Liver tissues of the DMBA+watercress (WS) group showed markedly reduced damage defined by less amount of mononuclear cell infiltration, hemorrhage, eosinophilic cells with a pyknotic nucleus $(\mathrm{p}<0.0001)$. Histopathological images of the control, DMBA, and DMBA+WS groups are shown in Figures 3, 4, and 5, respectively. In the control group, the normal parenchymal structure was observed in liver tissue (Figure $3(\mathbf{A}, \mathbf{B})$ ). There is no histological alteration of the central vein and surrounding hepatocytes in the portal areas. The liver tissue of the DMBA group (Figure 4 (A-E)) showed significantly histopathological damage. Liver necrosis (Figure $4(\mathrm{~A}, \mathrm{E})$ ), hepatocytes with a pyknotic nucleus and eosinophilic cytoplasm (Figure 4 $(A, B))$, hemorrhage (Figure $4(A, B))$, mononuclear cell infiltration (Figure $4(\mathrm{C})$ ), vascular congestion (Figure $4(\mathrm{C}, \mathrm{E})$ ), and sinusoidal dilatation (Figure $4(\mathrm{D})$ ) were observed. The liver tissue of the DMBA+WS group presented a decrease in histopathological damage. In liver tissue of the DMBA+WS group, a small amount of mononuclear cell infiltration (black arrows), hemorrhage (Figure 5 (A)), eosinophilic cells with a pyknotic nucleus (black arrows) were observed (Figure 5 (B)).

\section{Biochemical Findings}

Alterations in serum ALT level related to liver function are represented in Figure 6. It was observed that serum ALT level increased as a result of the application of DMBA, and then decreased in the DMBA+WS group $(p<0.05)$. The DNA binding activity level of the Nrf2 transcription factor was decreased significantly $(p<0.05)$ in the DMBA group, and a significant increase $(\mathrm{p}<0.05)$ was observed in the DMBA+WS group (Figure 7). Our results showed decreased activities of NQO1 and GST in the DMBA group. The administration of watercress significantly modulated the activities of NQO1 and GST (Figure 8). Furthermore, activities of SOD, GPx, and CAT were decreased in the DMBA group compared to the control and increased in the DMBA+WS group (Table 2). MDA levels were significantly elevated in the DMBA group and decreased by watercress administration (Table 2).

\begin{tabular}{|c|c|}
\hline Group & Histopathological damage score $($ Mean \pm SE) \\
\hline Control & $0.39 \pm 0.59^{a}$ \\
\hline DMBA & $2.11 \pm 0.88^{b}$ \\
\hline DMBA+watercress & $1.30 \pm 0.80^{c}$ \\
\hline \multicolumn{2}{|c|}{$\begin{array}{l}\text { Lowercase letters a, b, c in the same column show the differences between groups. } \\
\mathrm{p}<0.0001\end{array}$} \\
\hline
\end{tabular}

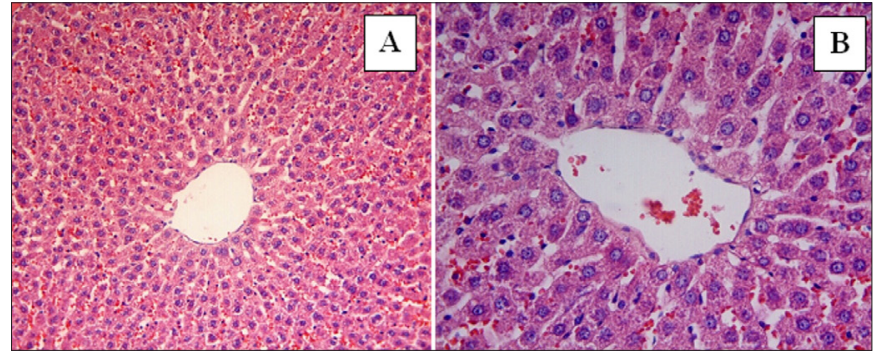

Figure 3. (A,B) Liver specimen from the control group showing a normal appearance. In the control group, liver tissue was normal histological and hepatocytes arranged in the form of cords around the vena centralis were observed. A: H-E; X20, B: H-E; X 40.

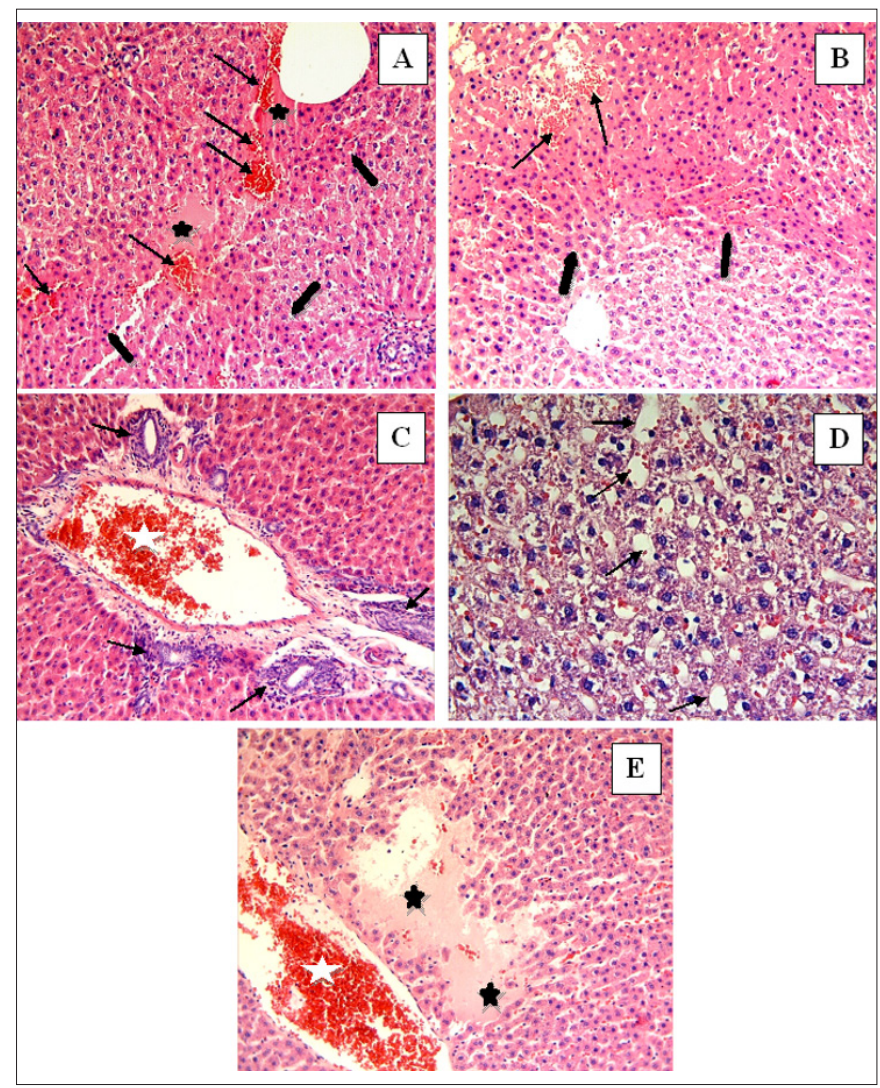

Figure 4. (A-E) Liver specimen from the DMBA-treated group. In the DMBA-treated group, necrosis of the liver tissue (black star) (A, E), hepatocytes with eosinophilic stained pyknotic nuclei (thick black arrows) (A, B), haemorrhage (thin black arrows) (A, B), mononuclear cell infiltration (thin black arrows) ) (C), vascular congestion (white star) (C, E) and sinusoidal dilatation (thin black arrows) (D) were observed. A, B, C, E: H-E; X20, D: H-E; X 40.

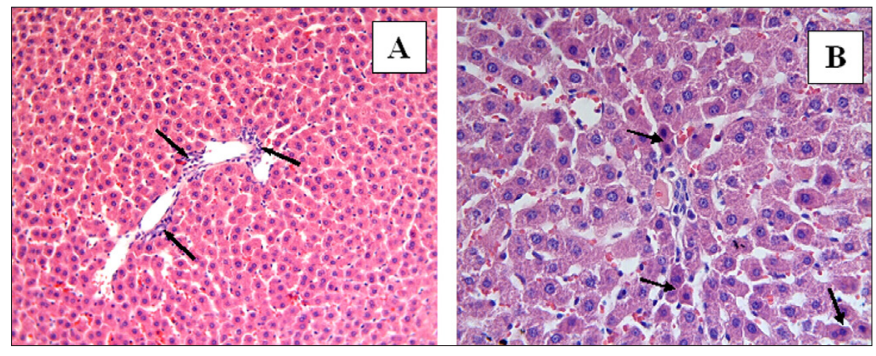

Figure 5. (A,B) Liver specimen from the DMBA+watercress group. In the DMBA+watercress group, mononuclear cell infiltration (black arrows) (A), haemorrhage (black arrows) (A), and hepatocytes with eosinophilic stained pyknotic nuclei (black arrows) (B) were observed. A: H-E; X 20, B: H-E; X 40. 


\begin{tabular}{|lcccc|}
\hline Table 2. Effects of DMBA and DMBA +Watercress treatments on antioxidant parameters in rat liver tissues. Data are presented as mean \pm SD \\
\hline Group (n) & CAT (U/mg protein) & SOD (U/mg protein) & GPx (U/mg protein) & MDA (nmol/mg protein) \\
\hline Control (9) & $7550.4 \pm 582.04$ & $38.398 \pm 11.7$ & $130.12 \pm 2.74$ & $134.97 \pm 9.42$ \\
DMBA (9) & $6642.2 \pm 521.69^{\mathrm{a}}$ & $19.272 \pm 6.02^{\mathrm{a}}$ & $108.23 \pm 4.59^{\mathrm{a}}$ & $212.46 \pm 8.57^{\mathrm{a}}$ \\
DMBA+Watercress (9) & $7425.4 \pm 262.54^{\mathrm{b}}$ & $67.691 \pm 14.9^{\mathrm{a}}$, & $118.66 \pm 3.92^{\mathrm{a}}$, & $152.98 \pm 3.07^{\mathrm{a}}$, \\
\hline${ }^{\mathrm{a}} \mathrm{p}<0.05$ compared to the control group; bp $<0.05$ compared to the DMBA group. & & \\
\hline
\end{tabular}

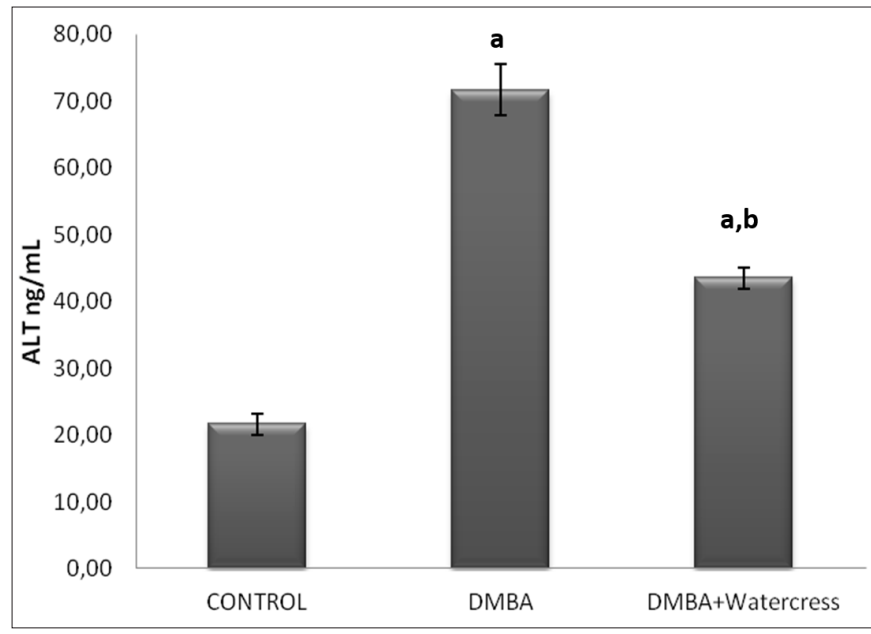

Figure 6. Serum ALT levels in all groups. Data are presented as mean \pm SD. ${ }^{a} p<0.05$ versus control; ${ }^{b} p<0.05$ versus DMBA

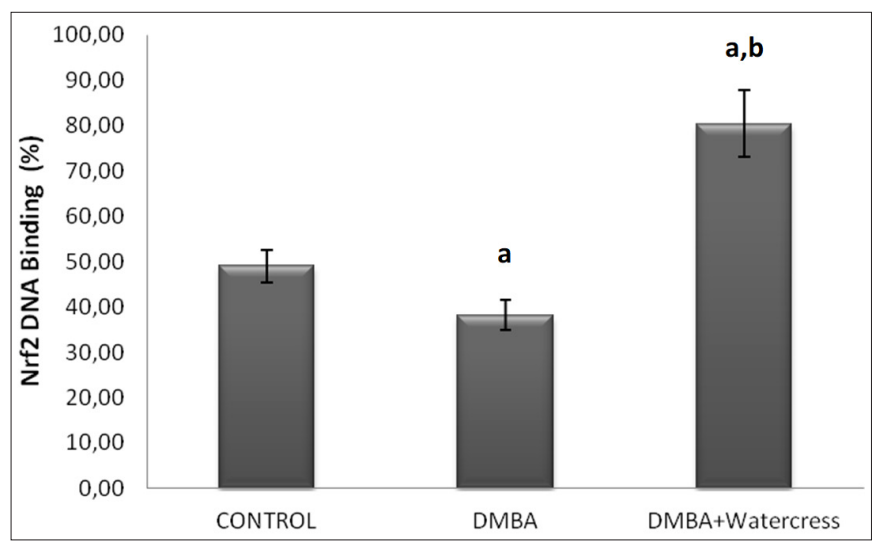

Figure 7. DNA binding activity level (\%) of Nrf2 transcription factor in all groups. Data are presented as mean \pm SD. ${ }^{\mathrm{a}} \mathrm{p}<0.05$ versus control; ${ }^{\mathrm{b}} \mathrm{p}<0.05$ versus DMBA

\section{DISCUSSION}

The present study investigated both histopathological and biochemically whether watercress has a protective effect in DMBA-induced liver injury by Nrf2/ARE signalling pathway. DMBA is a potent carcinogen and causes liver damage via reactive metabolites and oxidative stress (26). In this study, we used histopathological findings and serum ALT level to evaluate the severity of DMBA-induced liver damage. We observed that there was a significant increase in ALT level in the DMBA group in comparison to the control group. Administration of watercress caused a significant decrease in ALT level compared to the DMBA group. Moreover, the histopathological analysis showed normal parenchymal structure in the control group, whereas DMBA showed significant histopathological damage

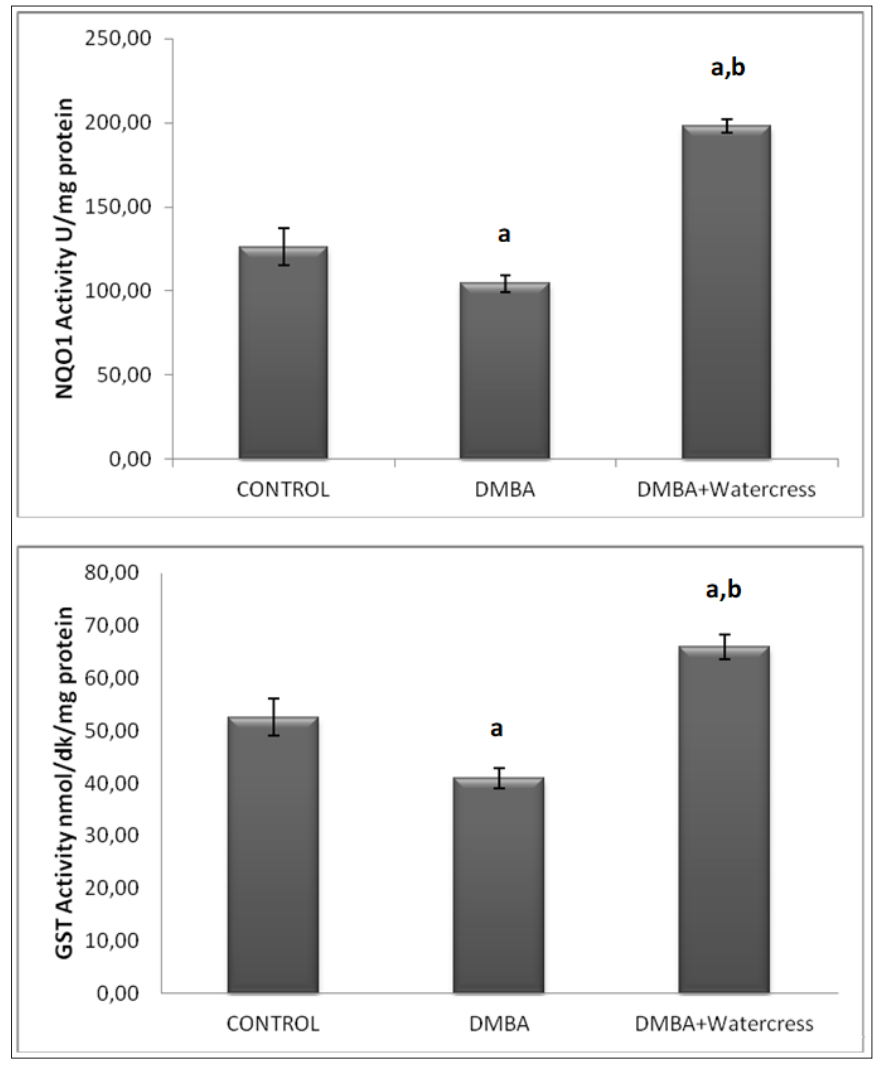

Figure 7. GST and NQO1 activities in all groups. Data are presented as mean \pm SD. ${ }^{a} \mathrm{p}<0.05$ versus control; ${ }^{b} \mathrm{p}<0.05$ versus DMBA

in the liver tissue. Reduction in histopathological damage was observed in the watercress treated group and a small amount of mononuclear cell infiltration, haemorrhage, eosinophilic stained pyknotic nucleus cells were observed. Taken together, histopathological data and serum ALT level of our study, we can suggest that watercress ameliorated DMBA-induced liver damage. In parallel with our results, Azarmehr et al. (27) reported that watercress has a hepatoprotective effect against acetaminophen-induced liver damage. Additionally, Doustimotlagh et al. (28) showed that Nasturtium officinale $\mathrm{R}$. $\mathrm{Br}$ and quercetin combination protected against cyclophosphamide-induced hepatotoxicity in rats.

Overproduction of ROS triggers serious damage to various cells associated with increased MDA level that is an important marker of lipid peroxidation and oxidative damage. In our study, the highest tissue MDA level was observed in the DMBA group. MDA level was significantly lower in the watercress group when compared with the DMBA group (29). Activities of 
SOD, CAT, GPx were significantly decreased in DMBAtreated rats when compared to control group and administration of watercress enhanced the activities of SOD, CAT, GPx. The alteration in antioxidant status increases the risk of oxidative damage to nucleic acids, proteins, lipids, and small intracellular molecules (30). Many experimental studies reported that enhancement of oxidative stress is contributed to DMBA-induced cancer (31). In this study, administration of watercress significantly reduced DMBA-induced elevation lipid peroxidation and also decreased the activities of liver enzymatic antioxidants. In line with our results, Sadeghi et al. (32) reported that hydroalcoholic extract of watercress ameliorated oxidative stress and liver injury in bile duct ligation-induced cholestatic rats by preventing the hepatic protein oxidation and enhancing the activity of the antioxidant enzymes.

It has been reported that up-regulation of Keap1 and down-regulation of Nrf2 expression increased cellular ROS (33). Nrf2-mediated antioxidant signalling pathways are critical for the prevention of oxidative stress-induced cell injury (34). It has been showed that various dietary phytochemicals target Nrf2/Keap1 signalling and induce the expression of antioxidant and phase II enzymes to inhibit the development of DMBAinduced carcinogenesis model (35). Our results revealed that the binding percentage of the Nrf2 transcription factor had a statistically significant decrease in the DMBA group comparison to the control group. In the watercress group, the percentage of Nrf2/ARE binding significantly was activated compared to the DMBA group. These results can be associated with sulfur-containing glucosinolate derivatives, such as PEITC. These natural isothiocyanates reduce Nrf2 degradation which results in the translocation to the nucleus of $\mathrm{Nrf2}$ (36). Previous studies reported that dietary isothiocyanates are an important cancer chemoprevention compound for the Nrf2/ARE system, which induces the activation and expression of phase II enzymes (37). Saravan et al. (38) were reported that thymoquinone protected liver tissue from DMBA toxicity by regulating phase I and phase II detoxification enzymes. In present study, there was a statistically significant decrease in phase II enzymes (NQO1 and GST) activities in the DMBA group compared to the control group. Administration of watercress significantly increased the activities of these enzymes compared to the DMBA group. According to our study, it can be suggested that there is a good correlation between the protective effect of watercress and supporting the DMBA detoxification by the Nrf2 signalling pathway. Induction of phase II detoxifying enzymes by $\mathrm{Nrf2}$ assists to eliminate toxic reactive intermediates generated via xenobiotic metabolism (39).
There are two major limitations for our study. First, we were only be able to measure ALT to evaluate the level of liver damage. Changes in ALT level were supported with histopathological analysis, but we could not measure other liver function parameters due to financial conditions. Another limitation is that we did not design and conduct a study on the molecular mechanism about which way watercress affects the Nrf2/ARE pathway. This topic has been planned for our future research.

Overall, this experimental study suggests that watercress ameliorated oxidative stress and liver injury through the regulation of antioxidant and phase II enzymes by the activation Nrf2/ARE signalling pathway in DMBAinduced liver damage in rats.

\section{CONCLUSION}

The study revealed that the watercress plant is effective through the activation of Nrf2/ARE signalling resulting in increased antioxidant and phase II detoxification enzyme activities which are important for the chemoprevention of liver damage caused by DMBA. Our data support that activation of Nrf2 is a promising strategy for chemoprevention. In this context, we think that watercress functions as an Nrf2 activator and effect of its PEITC content on the molecular mechanism should be investigated with further studies

\section{ETHICAL DECLARATIONS}

Ethics Committee Approval: The study was carried out with the permission of the Local Ethics Committee of the Animal Experiments of İnönü University (Date: 20/02/2015, Decision No: 2015/A-25).

Referee Evaluation Process: Externally peer-reviewed.

Conflict of Interest Statement: The authors have no conflicts of interest to declare.

Financial Disclosure: This study was supported by Scientific Research Projects Unit of İnönü University; Grant/Award Number: 2015/84.

Author Contributions: All of the authors declare that they have all participated in the design, execution, and analysis of the paper, and that they have approved the final version.

\section{REFERENCES}

1. Rengarajan T, Nandakumar N, Balasubramanian MP. D-Pinitol prevents rat breast carcinogenesis induced by 7,12-Dimethylbenz[a] anthracene through inhibition of $\mathrm{Bcl}-2$ and induction of $\mathrm{p} 53$, caspase- 3 proteins and modulation of hepatic biotransformation enzymes and antioxidants. Biomed Prev Nutr 2013; 3: 31-41.

2. Shimada T. Xenobiotic-metabolizing enzymes involved in activation and detoxification of carcinogenic polycyclic aromatic hydrocarbons. Drug Metab Pharmacokinet 2006; 21: 257-76. 
3. Xue W, Warshawsky D. Metabolic activation of polycyclic and heterocyclic aromatic hydrocarbons and DNA damage: a review. Toxicol Appl Pharmacol 2005; 206: 73-93.

4. Gelboin HV. Benzo[alpha]pyrene metabolism, activation and carcinogenesis: role and regulation of mixed-function oxidases and related enzymes. Physiol Rev 1980; 60: 1107-66.

5. Bharali R, Tabassum J, Azad MRH. Chemomodulatory effect of moringa oleifera, lam, on hepatic carcinogen metabolising enzymes, antioxidant parameters and skin papillomagenesis in mice. Asian Pac J Cancer Prev 2003; 4: 131-9.

6. Manzanares MÁ, Solanas M, Moral R, Escrich R, Vela E, Escrich E. Ontogeny of the major xenobiotic-metabolizing enzymes expression and the dietary lipids modulatory effect in the rat dimethylbenz(a)anthracene-induced breast cancer model. J Biochem Mol Toxicol 2014; 28: 539-48.

7. Li Y, Paonessa JD, Zhang, Y. Mechanism of chemical activation of Nrf2. PLoS ONE 2012; 7: e35122.

8. Baird L, Dinkova-Kostova AT. The cytoprotective role of the Keap1-Nrf2 pathway. Arch Toxicol 2011; 85: 241-72.

9. Klimek-Szczykutowicz M, Szopa A, Ekiert H. Chemical composition, traditional and professional use in medicine, application in environmental protection, position in food and cosmetics industries, and biotechnological studies of Nasturtium officinale (watercress) - a review. Fitoterapia 2018; 129: 283-92.

10. Ribeiro Rde A, de Barros F, de Melo MM, et al. Acute diuretic effects in conscious rats produced by some medicinal plants used in the state of São Paulo, Brasil. J Ethnopharmacol 1988; 24: 19-29.

11. Yaricsha CA, Rissyelly K. ACE inhibitory activity, Total phenolic and flavonoid content of watercress (Nasturtium officinale R. Br.) extract. Pharm J 2017; 9: 249-51.

12. Hoseini HF, Gohari AR, Saeidnia S, Majd NS, Hadjiakhoondi A. The effect of Nasturtium officinale on blood glucose level in diabetic rats. Pharmacol Ther 2009; 3: 866-71.

13. Bahramikia S, Yazdanparast R. Effect of hydroalcoholic extracts of Nasturtium officinale leaves on lipid profile in high-fat diet rats. J Ethnopharmacol 2008; 115: 116-21.

14. Camacho-Corona Mdel R, Ramírez-Cabrera MA, Santiago OG, Garza-González E, Palacios P, IdeLuna-Herrera J. Activity against drug resistant-tuberculosis strains of plants used in Mexican traditional medicine to treat tuberculosis and other respiratory diseases. Phytother Res 2008; 22: 82-5.

15. Boyd LA, McCann MJ, Hashim Y, Bennett RN, Gill CI, Rowland IR. Assessment of the anti-genotoxic, anti-proliferative, and antimetastatic potential of crude watercress extract in human colon cancer cells. Nutr Cancer 2006; 55: 232-41.

16. Giallourou N, Oruna-Concha MJ, Harbourne N. Effects of domestic processing methods on the phytochemical content of watercress (Nasturtium officinale). Food Chem 2016; 212: 411-9.

17. Talalay P, Fahey JW. Phytochemicals from cruciferous plants protect against cancer by modulating carcinogen metabolism. J Nutr 2001; 131: 3027-33.

18. Keum YS, Owuor ED, Kim BR, Hu R, Kong ANT. Involvement of Nrf2 and JNK1 in the activation of antioxidant responsive element (ARE) by chemopreventive agent phenethyl isothiocyanate (PEITC). Pharm Res 2003; 20: 1351-55.

19. Saarinen NM, Warri A, Airio M, Smeds A, Makela S. Role of dietary lignans in the reduction of breast cancer risk. Mol Nutr Food Res 2007; 51: 857-66.

20. Jiao D, Yu MC, Hankin JH, Low S-H, Chung F-L. Total isothiocyanate contents in cooked vegetables frequently consumed in Singapore. J Agric Food Chem 1998; 46: 1055-58.

21. Bradford MM. A rapid and sensitive method for the quantitation of microgram quantities of protein utilizing the principle of protein-dye binding. Anal Biochem 1976; 72: 248-54.

22. Beauchamp C, Fridovich I. Superoxide dismutase: Improved assays and an assay applicable to acrylamide gels. Anal Biochem 1971; 44: 276-87.
23. Lawrence RA, Burk RF. Glutathione peroxidase activity in selenium-deficient rat liver. Biochem Biophys Res Commun 1976; 71: 952-58.

24. Luck H. Catalase. In: Methods of Enzymatic Analysis, Bergmeyer HU (ed). Academic Press/Verlag Chemie, New York; 1963: 885-94.

25. Mihara M, Uchiyama M. Determination of malonaldehyde precursor in tissues by thiobarbituric acid test. Anal Biochem 1978; 86: 271-8.

26. Girolamia F. Time-dependent acetylsalicylic acid effects on liver CYP1A and antioxidant enzymes in a rat model of 7,12-dimethylbenzanthracene (DMBA)-induced mammary carcinogenesis. Toxicol Lett 2008; 181: 87-92.

27. Azarmehr N, Afshar P, Moradi M, et al. Hepatoprotective and antioxidant activity of watercress extract on acetaminopheninduced hepatotoxicity in rats. Heliyon 2019; 5: e02072.

28. Doustimotlagh AH, Kokhdan EP, Vakilpour H, et al. Protective effect of Nasturtium officinale $\mathrm{R}$. $\mathrm{Br}$ and quercetin against cyclophosphamide-induced hepatotoxicity in rats. Mol Biol Rep 2020; 47: 5001-12.

29. Gulbahce-Mutlu E, Baltaci SB, Menevse E, Mogulkoc R, Baltaci AK. The Effect of zinc and melatonin administration on lipid peroxidation, IL-6 levels, and element metabolism in DMBAinduced breast cancer in rats. Biol Trace Elem Res 2021; 199: 104451.

30. Saha SK, Lee SB, Won J, et al. Correlation between oxidative stress, nutrition, and cancer initiation. Int J Mol Sci 2017; 18: E1544.

31.Zeweil MM, Sadek KM, Taha NM, El-Sayed Y, Menshawy S. Graviola attenuates DMBA-induced breast cancer possibly through augmenting apoptosis and antioxidant pathway and downregulating estrogen receptors. Environ Sci Pollut Res Int 2019; 26: 15209-17.

32. Sadeghi H, Azarmehr N, Razmkhah F, et al. The hydroalcoholic extract of watercress attenuates protein oxidation, oxidative stress, and liver damage after bile duct ligation in rats. J Cell Biochem 2019; 120: 14875-84.

33. Sun T, Gao J, Han D, Shi H, Liu X. Fabrication and characterization of solid lipid nano-formulation of astraxanthin against DMBAinduced breast cancer via Nrf-2-Keap1 and NF-kB and mTOR/ Maf-1/PTEN pathway. Drug Deliv 2019; 26: 975-88.

34. Flocryk U, Lobodam A, Stachurska A, Jozkowicz A, Dulak J. Role of Nrf2 transcription factor in the cellular response to oxidative stress. Postepy Biochem 2010; 56: 147-55.

35. Kavitha K, Thiyagarajan P, Nandhini JR, Mishra R, Nagini S. Chemopreventive effects of diverse dietary phytochemicals against DMBA-induced hamster buccal pouch carcinogenesis via the induction of Nrf2-mediated cytoprotective antioxidant, detoxification, and DNA repair enzymes. Biochimie 2013; 95: 162939.

36. Yamamoto M, Kensler TW, Motohashi H. The Keap1-Nrf2 system: a thiol-based sensor-effector apparatus for maintaining redox homeostasis. Physiol Rev 2018; 98: 1169-203.

37. Konsue N, Ioannides C. Tissue differences in the modulation of rat cytochromes $\mathrm{P} 450$ and phase II conjugation systems by dietary doses of phenethyl isothiocyanate. Food Chem Toxicol 2008; 46: 3677-83.

38. Saravanan D, Baskaran K, Sakthisekaran D. Protective effect of thymoquinone on the liver tissues of 7, 12-dimethylbenz(a) anthracene induced experimental breast cancer rats. Asian J Pharm Clin Res 2016; 9: 197-201.

39. Ezzat SM, El-Halawany AM, Hamed AR, Abdel-Sattar E. Chapter 9-Role phytochemicals play in the activation of antioxidant response elements (AREs) and phase II enzymes and their relation to cancer progression and prevention. In: Studies in Natural Products Chemistry, Atta-ur-Rahman (ed). Elsevier, Volume 60; 2019: 345-69. 